Case Report

\title{
Histoid leprosy with ENL reaction
}

Pokhrel $K^{1}$, Ghimire $R^{2}$ and Subedi $S^{3}$

${ }^{1}$ Lecturer, Department of Dermatology, ${ }^{2}$ Lecturer, Department of Pathology, ${ }^{3}$ Lecturer, Department of Microbiology, Nepalgunj Medical College, Nepalgunj, Nepal

Funding: None

Conflicts of interest: None

\begin{abstract}
Keywords: Histoid Leprosy, ENL.

Correspondence:

Dr. Kumar Pokhrel

Lecturer, Department of Dermatology, Venereology and Leprology

Nepalgunj Medical College, BP Chowk, Chisapani, Nepalgunj, Nepal

E-mail: dr@kumarpokhrel.com.np
\end{abstract}

A case of 23 year old man with histoid leprosy who had ENL is being reported because of its late presentation. The patient had presented with history of skin colored shiny nodules on ankle, extensor part of lower limbs, forearm and pinna for 1 year. There was history of intermittent fever and joint pains of same duration. Slit skin smear from the lesion was positive for AFB. Histopathology of lesions was consistent with histoid leprosy. Patient was successfully treated with multidrug therapy. 


\section{Case Report}

\section{Introduction:}

Histoid leprosy is characterized by the presence of nodules which are firm to hard in consistency and are sharply delimited from the surrounding skin. ${ }^{1}$ Rarely, Histoid leprosy may undergo ENL reaction which is manifested histopathologically, as collection of histiocytes, neutrophils, lymphocytes and edema in the dermis.

\section{Case Report:}

A 23-year old man presented with complaints of pain in elbow and knee joint associated with intermittent fever and nasal stuffiness, and epistaxis from right nose and skin colored shiny nodules on right hand since 1 year. After 3 months of initial nodule on hand, he developed multiple, discrete, firm to hard nodules on ankle, extensor part of lower limbs, forearm and pinna. Some of these nodules were painful. Patient noticed softening of the nodules on legs and feet followed by ulceration and crusting without purulent discharge since last 2 months. These lesions were not responding to usual antibiotics.

On cutaneous examination, multiple ulcers with raised boarder and depressed center with adherent crust over an ill defined erythematous infiltrated base, which was mild tender on palpation. These lesions were typically situated on ankle region. There were multiple, discrete, cutaneous and subcutaneous, skin colored, shiny papules over both pinnae and firm nodules on both upper and lower limbs distributed bilaterally and symmetrically. Single firmed nodule on the hard

Figure 1. Photographs before treatment palate of buccal cavity was found. The size of nodules varied from 0.5 to $1.0 \mathrm{~cm}$. There was no thickening and/or tenderness of peripheral nerves. Hair, nails and mucous membranes were normal.

The patient was started on multidrug therapy (MDT) 3years back , unfortunately he took these medicine only for 7 days. Treatment default was of unknown reason. Patient develop pain in elbow and knee regions and intermittent fever after 2 years of stopping MDT drugs, followed by development of firmed shiny nodules, some of which ultimately softened and ulcerated. Laboratory investigations like haemogram, blood glucose, liver and kidney function tests were normal. The culture from the base of the ulcer was sterile. Slit skin smear examination from lesions of ears was positive for AFB (ZiehlNielsen stain) and negative for LD bodies (Giemsa stain). Elliptical Skin biopsy from a firm nodule on foot showed tumorous collections of spindle shaped cells arranged in a criss-cross fashion, collection of histiocytes, neutrophils, lymphocytes and edema in the dermis along with infiltration of the vessel wall by neutrophils and deposition of fibrinoid material.

Patient was again started MDT for 12 months due to his default treatment. The lesions were regressed during examination after 2 months of MDT. Patient was properly counseled to take medicine (MDT) and to follow up regularly.
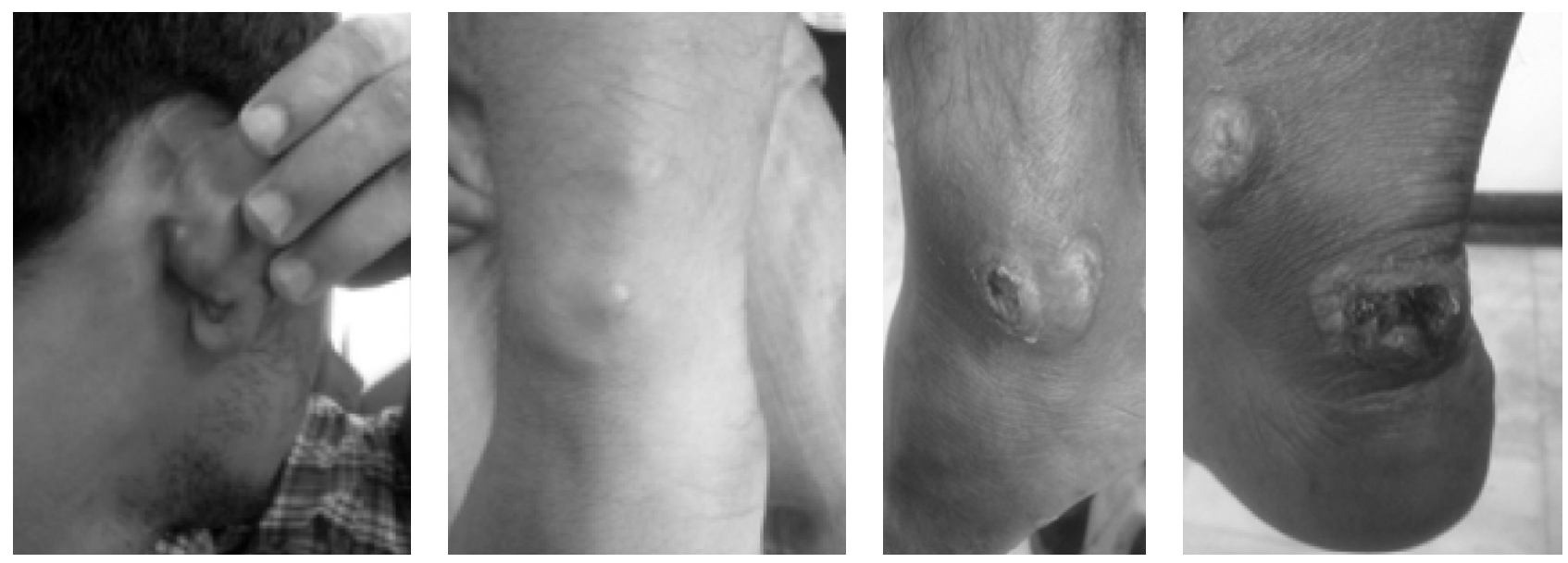


\section{Case Report}

Figure 2. Photographs after treatment (MDT)
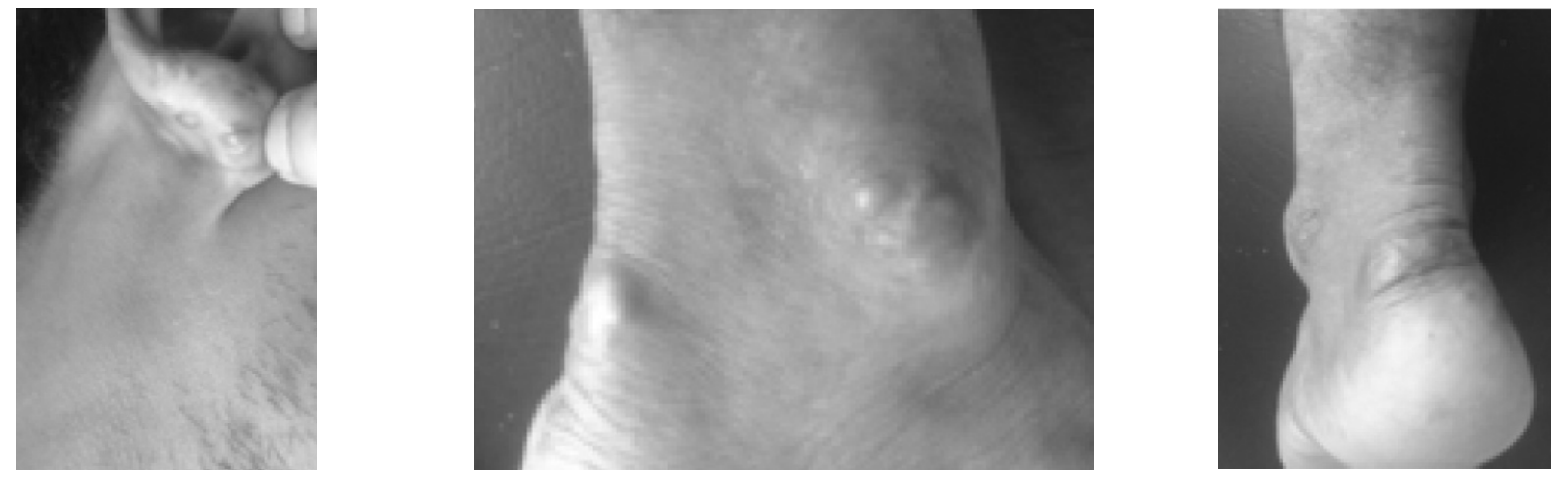

\section{Discussion:}

Histoid leprosy in rare instances undergoes ENL reaction which has rarely been documented in histoid leprosy. In 1963, Wade ${ }^{2}$ described cutaneous and subcutaneous histoid nodules in lepromatous leprosy cases. These nodules may occasionally manifest central softening. These cases did not undergo ENL type of reaction. Bhutani. ${ }^{3}$ In 1974 found classical ENL reaction in three of his twenty patients of histoid leprosy which occurred during sulphone therapy, However, Sharma $\mathrm{SK}^{4}$ et al have reported that in histoid lepromatous cases there was a tendency for softening to occur in the centre of the nodule and in some instances this was a prelude to the occurrence of pustules and ulcerating type of reaction. These complications took the form of acute exacerbation of the existing lesions, classical lepra reaction, lepra reaction with pustulation in lesions, ulceration of nodules with or without the constitutional symptoms or ENL alone. In our case, few nodules on the lower legs showed softening, ulceration and without discharge which typically occured after two and half ( 2.5 years) years of MDT default with other feature of type 2 reaction (Intermittent fever and joint pain). Skin biopsy from these lesions confirmed Histoid leprosy with ENL reaction. The features of our case were similar to the cases reported by Sharma SK ${ }^{4}$ et al.

\section{Conclusion:}

Histoid leprosy may not always present as firmed, non tender and skin colored nodules but occasionally may manifest as soft, tender, erythematous and ulcerative nodules which may mimic other chronic ulcerative dermatoses.

\section{References}

1. Nunzi E, Fiallo P. Differential diagnosis. In Leprosy 2nd Ed. Edited by Hasting R C, Opromolla DVA, Churchill Livingstone, Edinburgh. 1994;p. 291-313.

2. Wade H W. The histoid variety of lepromatous leprosy. Int J Lep 1963;31:12942.

3. Bhutani L K, Bedi T R, Malhotra Y K, kandhari KC ,Deo MG. Histoid leprosy in North India. Int J Lep 1974;42:174-181. Sharma SK, Rath N, Gautam RK, Sharma PK, Jain RK, Kar HK. Histoid leprosy with ENL reaction. Indian J Dermatol Venereol Leprol 2002;68:342-3 